26. Barnett SA, Rusch VW, Zheng J, Park BJ, Rizk NP, Plourde G, et al. Contemporary results of surgical resection of non-small cell lung cancer after induction therapy: a review of 549 consecutive cases. J Thorac Oncol. 2011;6: 1530-6.

27. Weder W, Collaud S, Eberhardt WE, Hillinger S, Welter S, Stahel R, et al. Pneumonectomy is a valuable treatment option after neoadjuvant therapy for stage III non-small-cell lung cancer. J Thorac Cardiovasc Surg. 2010;139: 1424-30.

28. Hu Y, McMurry TL, Wells KM, Isbell JM, Stukenborg GJ, Kozower BD. Postoperative mortality is an inadequate quality indicator for lung cancer resection. Ann Thorac Surg. 2014;97:973-9.

29. Vanderweele TJ, Arah OA. Bias formulas for sensitivity analysis of unmeasured confounding for general outcomes, treatments, and confounders. Epidemiology. 2011;22:42-52.

30. NSCLC Meta-analysis Collaborative Group. Preoperative chemotherapy for non-small cell lung cancer: a systematic review and meta-analysis of individual participant data. Lancet. 2014;383:1561-71.

\section{Discussion}

Dr Frank Detterbeck (New Haven, Conn). This is a great article, and it helps to refocus our discussion a bit. The 0139 study has influenced us a lot, although I think Tony Kim showed that it was a statistical outlier. I think it's not about pneumonectomy, but about perioperative mortality, and you have shown us that perioperative mortality for pneumonectomy, even after neoadjuvant therapy, isn't necessarily so high that we need to always avoid it. One of the things, though, is that this is in the context of a very organized system. Can you tell us more about that? When was that started? Was that stable throughout the time period? Did that evolve throughout the time period? What is the average number of lung resections per institution in the database so we can compare that with our own system?

Dr Thomas. The first cancer plan was launched in 2003, as I showed in my pictures, and it has been effective since 2007 . The main fact is that now it is completely forbidden for a general surgeon to deal with lung cancer surgery. This is one of the most striking results of this cancer plan. The second point is about the minimal level of activity. With these data, we are not able to show any impact of this measure since EPITHOR was launched by the French Society of Thoracic and Cardiovascular Surgeons. That means that those centers participating in EPITHOR were not affected by the establishment of this threshold. As a matter of fact, two thirds of the centers practicing thoracic surgery were closed, but it represented only $12 \%$ of all lung cancer surgery in France. In EPITHOR, only 6 centers had to be regrouped. They were not closed. They were regrouped to comply with this minimal threshold of activity. So we were unable to see any impact of this measure with the data collected in EPITHOR. Regarding the volume of activity, tomorrow, Pierre Falcoz will present a study we have performed showing that, provided these preliminary requisites, the volume of the institution by itself had no impact on the outcome in our health system organization.

Dr Detterbeck. What is the average number of resections in France so that I can compare it with the United States?

Dr Thomas. It's difficult to say. When I presented the data for lobectomy, it was approximately 30,000 lobectomies in a 10-year period, and now, approximately 5000 pneumonectomies in a 10-year period.
Dr Detterbeck. Okay. So your incidence of pneumonectomy decreased a lot, from approximately $20 \%$ to less than $10 \%$. Why is that? Is that because there is less squamous cell now and more adenocarcinoma? Is it because there are more sleeve resections? Is it because there is more selection of patients and there are just less operations overall? Does that have anything to do with the operative mortality decreasing over time?

Dr Thomas. Well, it's impossible to answer with the data inside EPITHOR. Last year, we investigated the incidence of sleeve lobectomy to see if there was a change during the last 10 years. There was no change. The overall proportion was approximately $5 \%$, and it didn't change during the last decade. I think it is predominantly a selection process, and this selection began with the oncologists who do not refer these patients to a surgeon anymore, especially when they have a right-sided tumor and if the operation would be pneumonectomy. Therefore, there is a diminishment of this operation. Our results clearly show that in expert centers at least, with certified thoracic surgeons, induction chemotherapy is not an issue.

Dr Detterbeck. In your propensity matching, I wonder if you shouldn't include the time period, early versus late cases. I don't think you did that. I wonder if you shouldn't, because things have changed a fair amount during the time period.

Dr Thomas. That is an excellent point, but we didn't.

Dr Mark Krasna (Neptune, $N J$ ). It was an excellent presentation, and I commend the Committee. This is the second excellent presentation today that shows the ability to perform pneumonectomy with a decreasing mortality over the last 10 years.

The last comment you made is worth reiterating. There is still a place for pneumonectomy in patients with non-small cell lung cancer who are well selected but who otherwise may have no other option, and it is crucial for us not to demonize the procedure because of the results of 0139 or any other single series. Again, I commend you and others and my former colleagues. There are now many series, and we had a pro/con debate here 2 years ago where we showed that in centers committed to performing this procedure, it can be done safely, with $0 \%$ to $10 \%$ mortality.

One specific question I would like to ask you about is the induction cases. It is, of course, counterintuitive but nice to think that induction therapy helped patients and caused a decrease in mortality. The only thing I can think of that would happen in my hands that might cause that is because I'm so careful in patients with induction therapy. I routinely use muscle flaps and other fluidconserving therapy. You mentioned to us that you didn't have information on fluid management. Did the majority of these patients who did have induction therapy have a flap, whether it was a muscle flap or any other kind of flap, that helped protect the bronchus?

Dr Thomas. I cannot answer your specific question with the data inside EPITHOR, but I can answer as one of the contributing centers. I can also answer as the main author of the recommendations for the French national guidelines in the surgical practices. Yes, these patients definitely are not managed as usual. As you mentioned, fluid management is strict and rigorous in those patients, and all these patients now receive a flap to reinforce the bronchial sutures. Also, at least in my institution, we remove the chest tube early to avoid all these bad things that could occur with the mediastinal shift and so on. Definitely, I think there is a management bias. 
Dr Sudish Murthy (Cleveland, Ohio). The audience has to recognize that induction chemotherapy is a different breed of cat than induction chemoradiation therapy, and that is where most of our data are generated from. The other thing about propensity analysis is that it takes a fair bit of bias of thinking what is going to affect the outcome in this patient group to come up with the variables that you need to impute into these algorithms. The fewer the variables, the less strenuous your matching algorithms are. When you have these large databases, they are only matching on 5 variables?

Dr Thomas. Nine variables.

Dr Murthy. With only 9 variables, you will no doubt lose some granularity in terms of pseudo-randomization.

\title{
EDITORIAL COMMENTARY
}

\section{A French connection}

\author{
Sudish C. Murthy, MD, PhD
}

See related article on pages 73-83.

Perhaps it's time for the STS (Society of Thoracic Surgeons) and SEER (Surveillance, Epidemiology, and End Results) databases to move over: There's a new sheriff in town. This issue contains a large study of pneumonectomy patients from France, the substrate of which is the EPITHOR database (French Society of Thoracic and Cardiovascular Surgery database). Data on nearly 4500 patients were able to be accessed, and we are all witnesses to the fruits of mining this database. The French report a nationwide mortality of just below $8 \%$ for pneumonectomy and identify the risks of early mortality and a few curious protective factors. The sheer size of the study immediately makes it interesting, regardless of the actual findings.

Some bias seems to exist against large database studies generated outside the United States, especially when the findings reflect a better outcome for patients than we report from our own US national registries or databases. Lung cancer survival in Japan trumps that in the United States on a stage-for-stage basis. The same could be said for management of gastric cancer. Perhaps we in the United States find this insulting and worry that it somehow brings our own capabilities into question. Our usual response to these types of reports is to write editorials that point out some ambiguity in the database, or mistake in the statistical analysis, as a principal reason for the survival advantage. Unfortunately, we often ignore the expert care and

\footnotetext{
From the Cleveland Clinic Foundation, Cleveland, Ohio.

Disclosures: Author has nothing to disclose with regard to commercial support.

Received for publication Oct 22, 2014; accepted for publication Oct 22, 2014

Address for reprints: Sudish C. Murthy, MD, PhD, Cleveland Clinic Foundation/Desk

J4-1, Thoracic and Cardiovascular Surgery, 9500 Euclid Ave, Cleveland, OH

44195 (E-mail: murthys1@ccf.org).

J Thorac Cardiovasc Surg 2015;149:83-4

$0022-5223 / \$ 36.00$

Copyright (c) 2015 by The American Association for Thoracic Surgery

http://dx.doi.org/10.1016/j.jtcvs.2014.10.098
}

management of these patients and fail to consider that the presentation of the disease and response to therapy might simply be different elsewhere in the world.

To evaluate this possibility, the French database EPITHOR has served as the basis for a study of pneumonectomy for lung cancer. This data repository, as well as those created elsewhere in Europe, is part of a greater quality initiative and represents an attempt to standardize care across the country. EPITHOR is more than a registry, and surprisingly, contains fairly detailed information on postoperative complications that is used in this study. Because of the relative granularity of the database, the authors were able to perform modern comparative analytic techniques, including propensity matching, to fortify their conclusions. Most of their findings are in keeping with common sense and are not grossly dissimilar from results reported in this country, which I'm sure will be a relief to our US readership. A nationwide mortality of slightly less than $8 \%$ (over the past decade) is commendable. Risks for poor early outcome include age, low body mass index (BMI, a suspected surrogate for malnutrition), and poor performance status.

Curiously, these French authors also identify induction therapy and "overweight" BMI as "protective factors" after pneumonectomy. I suspect this should not be taken literally by the reader as an injunction to fatten up one's patients and inject them with systemic poisons just before taking them out to the proverbial woodshed for an old-fashioned beating to optimize outcome. Rather, these variables are likely surrogates for a more robust and hardy stock, and as with all large databases, this is where the facts end, and the speculation, conjecture, and innuendo begin.

It is easy to lose one's clinical perspective during a large number-crunching exercise such as this. "Statistics this" and " $P$ value that" are great up to a certain point, at which clinical gestalt must reign supreme. French "overweight" is probably the equivalent of American "healthy." Most in the 